\title{
Investigation of methane adsorption mechanism on Longmaxi shale by combining the micropore filling and monolayer coverage theories
}

\author{
Shangwen Zhou ${ }^{1,2 *}$, Yang Ning ${ }^{3}$, Hongyan Wang ${ }^{1,2}$, Honglin Liu ${ }^{1,2}$, Huaqing Xue ${ }^{1,2}$ \\ ${ }^{1}$ PetroChina Research Institute of Petroleum Exploration \& Development, Beijing 100083, P. R. China \\ ${ }^{2}$ National Energy Shale Gas R\&D (Experiment) Center, Langfang 065007, P. R. China \\ ${ }^{3}$ Department of Petroleum Engineering, University of Houston, Houston, Texas 77204, USA \\ (Received June 1, 2018; revised June 21, 2018; accepted June 22, 2018; available online June 28, 2018)
}

\section{Citation:}

Zhou, S., Ning, Y., Wang, H., Liu, H.,

Xue, H. Investigation of methane

adsorption mechanism on Longmaxi shale

by combining the micropore filling and

monolayer coverage theories. Advances in

Geo-Energy Research, 2018, 2(3):

269-281, doi: 10.26804/ager.2018.03.05.

Corresponding author:

*E-mail: zhousw10@ petrochina.com.cn

Keywords:

Shale gas

adsorption mechanism

micropore filling

monolayer adsorption

nanopores

adsorption model

\begin{abstract}
:
Understanding the methane adsorption mechanism is critical for studying shale gas storage and transport in shale nanopores. In this work, we conducted low-pressure nitrogen adsorption (LPNA), scanning electron microscopy (SEM), and high-pressure methane adsorption experiments on seven shale samples from the Longmaxi formation in Sichuan basin. LPNA and SEM results show that pores in the shale samples are mainly nanometersized and have a broad size distribution. We have also shown that methane should be not only adsorbed in micropores $(<2 \mathrm{~nm})$ but also in mesopores $(2-50 \mathrm{~nm})$ by two hypotheses. Therefore, we established a novel DA-LF model by combining the micropore filling and monolayer coverage theories to describe the methane adsorption process in shale. This new model can fit the high-pressure isotherms quite well, and the fitting error of this new model is slightly smaller than the commonly used D-A and L-F models. The absolute adsorption isotherms and the capacities for micropores and mesopores can be calculated using this new model separately, showing that $77 \%$ to $97 \%$ of methane molecules are adsorbed in micropores. In addition, we conclude that the methane adsorption mechanism in shale is: the majority of methane molecules are filled in micropores, and the remainder are monolayer-adsorbed in mesopores. It is anticipated that our results provide a more accurate explanation of the shale gas adsorption mechanism in shale formations.
\end{abstract}

\section{Introduction}

Shale gas has received increasing attentions in recent years due to its remarkable success of commercial production in North America (Ambrose et al., 2012), which has also promoted the development of shale gas in many other countries. The exploration and development of shale gas reservoirs in China, particularly in southern Sichuan Basin, has made significant progress in the past few years (Zou et al., 2015). Shale gas reservoirs differ from most of conventional gas reservoirs including sandstone and carbonate because shale gas formation is both source rock and reservoir storing natural gas (Ambrose et al., 2012; Zou et al., 2015). Another significant difference is that a large proportion of total gas content is in the adsorbed state (Curtis et al., 2002; Zou et al., 2015). It is no doubt that the quantity of adsorbed gas is significant for accurate estimations of total gas-in-place and predictions of shale gas productions (Curtis et al., 2002; Montgomery et al., 2005; Ambrose et al., 2010).

The adsorption characteristics of shale gas has been studied intensively in the last decade, mainly by experiments and molecular simulations (Clarkson et al., 2013; Mosher et al., 2013; Rexer et al., 2013; He et al., 2016; Tang et al., 2016; Tian et al., 2016; Xiong et al., 2017). Extensive studies on the methane adsorption capacity and its controlling factors in various shale formations have been conducted, showing that the total organic carbon (TOC) is a main contributor to the adsorbed gas capacity (Ross et al., 2009; Weniger et al., 2010; Gasparik et al., 2012; Zhang et al., 2012; Ji et al., 2015; Wang et al., 2016a; Zhao et al., 2017). In addition, methane in shale formations is typically in the supercritical state as the formation temperature and pressure far exceed its critical properties $\left(-82.5^{\circ} \mathrm{C}\right.$ and 4.64 $\mathrm{MPa}$ ) (Aranovich and Donohue, 
1996; Do and Do, 2003). As for the adsorption of supercritical methane in shale, a common consensus has been established that the observed (excess) adsorption isotherms decrease in the high-pressure range (Do and Do, 2003; Gasparik et al., 2012; Tang et al., 2016; Tian et al., 2016; Zhou et al., 2018b). Hence, the key issues remaining in this field is how to model these excess adsorption isotherms and reveal the real adsorption mechanism of shale gas under formation conditions.

Many adsorption models have been proposed to characterize the methane adsorption process under the formation temperature and pressure, including Langmuir (Tang et al., 2016), Langmuir-Freundlich (L-F) (Wang et al., 2016c), OnoKondo (Bi et al., 2016), simplified local-density (SLD) (Chareonsuppanimit et al., 2012), Dubinin-Radushkevich (D-R) and Dubinin-Astakhov (D-A) models (Sakurovs et al., 2016). Researchers have attempted to reveal methane adsorption mechanisms in shale using these models (Zhou et al., 2003; Tian et al., 2016; Li et al., 2017). However, these models were originally established based on a variety of assumptions. For example, the Langmuir model assumes that gas molecules are monolayer-adsorbed in adsorbents, and the surface of the solid adsorbent is homogeneous with a constant adsorption heat, which is over-simplified to describe complicated situations in shale gas reservoirs (Langmuir et al., 1918; Tang et al., 2016). Although the Langmuir model fits some experimental isotherms quite well (Zhang et al., 2012; Yu et al., 2014; Tian et al., 2016), it cannot be concluded that the methane adsorption mechanism is monolayer adsorption. Therefore, we cannot determine its mechanism by those models as all the equations showing similar fitting effect (Sakurovs et al., 2007; Wang et al., 2016c). In other words, we are unable to explain the adsorption mechanism by a model only based on the quality of curve fitting. A suitable model should have the fact that, its internal hypothesis is consistent with the real characteristics of shale. Therefore, an adsorption model considering the complexity and heterogeneity of shale pore structures, which most of adsorption models have ignored, is critically needed.

Pores are the basis of shale gas accumulation and seriously affect the adsorption properties of shale (Milliken et al., 2013; Tian et al., 2013). The pore structures in shale have been widely analyzed using fluid invasion and microscopic observation methods, such as low temperature $\mathrm{N}_{2} / \mathrm{CO}_{2}$ adsorption, high pressure mercury injection, nuclear magnetic resonance (NMR) and field emission scanning electron microscopy (FESEM) and so on (Tian et al., 2013; Jiao et al., 2014; Zhao et al., 2018). Almost all the experiments on Longmaxi shales have indicated that pores are nanometer-sized and exist dominantly in organic matter (Tian et al., 2013; Zhou et al., 2016). Organic-rich shale has a broad pore size distribution with a significant proportion of micropores $(<2 \mathrm{~nm})$, mesopores $(2-$ $50 \mathrm{~nm}$ ), and macropores ( $>50 \mathrm{~nm}$ ) according to the pore size classification of the International Union of Pure and Applied Chemistry (IUPAC) (Sing et al., 1985). However, the mechanisms of gas adsorption are different in micropores and mesopores (Dubinin, 1967; Findnegg, 1983; Li et al., 2017). In micropores, gas molecules are adsorbed in the form of pore filling (Dubinin, 1967), which is caused by the overlapping of the adsorption potential from both sides of the pore wall surfaces (Mosher et al., 2013). On the other hand, in mesopores, gas molecules are adsorbed as a single layer on the pore wall surfaces (Do and Do, 2003). We can conclude that the adsorption mechanisms and capacities depend on the characteristics of pore wall surfaces in both micropores and mesopores. Therefore, pore filling in micropores and monolayer adsorption in mesopores might occur simultaneously during the process of methane adsorption.

In our previous work (Zhou et al., 2018b), we have demonstrated that the adsorbed methane is stored not only in micropores but also in mesopores through the analysis of adsorbed-phase volume, which lays a foundation to investigate the shale gas adsorption mechanism. Based upon previous discoveries, the objective of this study is to propose a novel adsorption model considering the different mechanisms of methane adsorption in micropores and mesopores. In order to prove the validity of the proposed model, we fitted the methane adsorption isotherms at pressures up to $25.0 \mathrm{MPa}$. Moreover, we compared it with other commonly used models to elucidate the advantages of the new model. It is anticipated that our results provide more accurate explanations of the true adsorption mechanisms in shale formations.

\section{Theoretical basis}

\subsection{Micropore filling theory}

The micropore filling theory was first proposed by Dubinin to study vapor adsorption in microporous solids (Dubinin, 1967). This theory assumes that the adsorbate fills the adsorption space via the mechanism of volume filling, and hence it does not form discrete monolayers in micropores (Dubinin and Astakhov, 1971). Because of the small pore diameter, the force field generated between two pore walls is superimposed, which makes the micropores more attractive to adsorbed molecules. The adsorbed molecules do not cover the pore walls but fill the bulk regions in a near-liquid state (Wang et al., 2016c). Therefore, the vapor adsorption by micropores is enhanced even at a very low pressure.

Based on the micropore filling theory and Polanyi adsorption potential theory, the Dubinin-Radushkevich (D-R) and Dubinin-Astakhov (D-A) equations have been developed to model Type I adsorption isotherms (Foo and Hameed, 2010; Pini et al., 2010; Ushiki et al., 2013; Hao et al., 2014). The two equations were considered to provide an appropriate description of the adsorption phenomena occurring in the adsorbent micropores. The D-A adsorption model can be expressed by Eq. (1) and can be further simplified to D-R equation when $k=2$ (Dubinin and Astakhov, 1971).

$$
n_{\mathrm{ab}}=n_{0} \exp \left\{-D\left[\ln \left(\frac{p_{0}}{p}\right)\right]^{k}\right\}
$$

where $n_{a b}$ is the absolute adsorption capacity, and $n_{0}$ is the maximum absolute adsorption capacity of micropore filling. $D$ is a parameter related to the pore structure through $D=$ $(R T / \beta E)^{k}$, where $E$ is the characteristic energy and $\beta$ is the 
Table 1. The TOC, pore surface area and pore volume of the shale samples (Zhou et al., 2018a).

\begin{tabular}{lllllllll}
\hline \multirow{2}{*}{ Sample } & Depth & TOC & $\mathrm{S}_{\text {BET }}$ & $\mathrm{S}_{\text {micro }}$ & $S_{B J H}$ & $V_{\text {BET }}$ & $V_{\text {micro }}$ & $V_{\text {BJH }}$ \\
\cline { 2 - 9 } & $(\mathrm{m})$ & $(\%)$ & $\left(\mathrm{m}^{2} / \mathrm{g}\right)$ & $\left(\mathrm{m}^{2} / \mathrm{g}\right)$ & $\left(\mathrm{m}^{2} / \mathrm{g}\right)$ & $\left(\mathrm{cm}^{3} / \mathrm{g}\right)$ & $\left(\mathrm{cm}^{3} / \mathrm{g}\right)$ & $\left(\mathrm{cm}^{3} / \mathrm{g}\right)$ \\
\hline $\mathrm{X} 2-1$ & $1,955.67$ & 4.1 & 23.43 & 7.81 & 13.85 & 0.03340 & 0.00407 & 0.02889 \\
$\mathrm{X} 2-2$ & $1,976.46$ & 5.3 & 19.65 & 7.02 & 11.00 & 0.02837 & 0.00370 & 0.02424 \\
$\mathrm{X} 2-3$ & $1,981.00$ & 5.8 & 22.60 & 8.31 & 12.40 & 0.02813 & 0.00437 & 0.02325 \\
$\mathrm{X} 2-4$ & $1,982.73$ & 2.8 & 16.06 & 4.45 & 10.57 & 0.02694 & 0.00232 & 0.02443 \\
$\mathrm{X} 3-1$ & $2,364.54$ & 3.1 & 9.83 & 2.22 & 7.64 & 0.02305 & 0.00115 & 0.02184 \\
$\mathrm{X} 3-2$ & $2,411.88$ & 4.3 & 11.81 & 3.22 & 8.91 & 0.02314 & 0.00168 & 0.02172 \\
$\mathrm{X} 3-3$ & $2,437.57$ & 3.7 & 12.17 & 3.64 & 8.81 & 0.02284 & 0.00191 & 0.02125 \\
\hline
\end{tabular}

$S_{B E T}$ and $V_{B E T}$, the total surface area and volume by the BET equation (Brunauer et al., 1936); $S_{\text {micro }}$ and $V_{\text {micro, }}$, the surface area and volume of micropores $(<2 \mathrm{~nm})$ by the t-plot equation (Mikhail et al., 1968); $S_{B J H}$ and $V_{B J H}$, the surface area and volume of meso-macropores (2-200 $\mathrm{nm}$ ) by the BJH equation (Sing et al., 1985).

coefficient of adsorbate affinity. In Eq. (1), $p_{0}$ is the saturation vapor pressure of the adsorbate at temperature $T, p$ is the equilibrium pressure, and $k$ is the structural heterogeneity parameter. Notice that the parameter $p_{0}$ in D-R and D-A equations cannot be physically defined for a gas above its critical temperature $T_{c}$ (Clarkson et al., 1997; Do, 1998). Although some scholars have defined a pseudo-saturation vapor pressure $\left(p_{s}\right)$ to replace $p_{0}$ (Amankwah and Schwarz, 1995; Clarkson et al., 1997; Do, 1998; Hao et al., 2014; Yu et al., 2014), the adapted equations are rather empirical and lack a physical basis (Sakurovs, 2007). Sakurovs and his coworkers have modified the D-R equation by replacing $p_{0}$ and $p$ with the adsorbed-phase density $\left(\rho_{a}\right)$ and the bulk gas density $\left(\rho_{g}\right)$, and then their modified model has been widely used to describe gas adsorption under supercritical conditions. The supercritical D-A absolute adsorption model can be expressed as (Sakurovs, 2007):

$$
n_{\mathrm{ab}}=n_{0} \exp \left\{-D\left[\ln \left(\frac{\rho_{\mathrm{a}}}{\rho_{\mathrm{g}}}\right)\right]^{k}\right\}
$$

The observed adsorption capacity is the excess adsorption capacity $\left(n_{e x}\right)$ in high-pressure isothermal adsorption experiments, so that the absolute adsorption should be transformed to the excess adsorption by fitting the experimental isotherms through the following equation (Zhou et al., 2018b).

$$
n_{e x}=n_{a b}\left(1-\frac{\rho_{g}}{\rho_{a}}\right)
$$

Consequently, the DA-based excess adsorption model can be rewritten as

$$
n_{\mathrm{ex}}=n_{0} \exp \left\{-D\left[\ln \left(\frac{\rho_{\mathrm{a}}}{\rho_{\mathrm{g}}}\right)\right]^{k}\right\}\left(1-\frac{\rho_{\mathrm{g}}}{\rho_{\mathrm{a}}}\right)
$$

\subsection{Monolayer coverage theory}

The monolayer coverage theory was proposed by Langmuir (Langmuir, 1918), assuming only a single layer of molecules covering solid surfaces during the adsorption process. Moreover, this theory is also based on the assumptions of homogeneous pore surface and no interaction between neighboring molecules. Integrating those ideal conditions, the Langmuir equation can be derived from the kinetic theory of gases or the statistical thermodynamics (Yang, 1987). The Langmuir model is the most widely used model in coals and shales because of its simplicity, effectiveness, and the reasonable explanation of its parameters (Tang, 2017). Langmuir model is expressed as

$$
n_{a b}=\frac{n_{L} p}{p+p_{L}}
$$

where $n_{L}$ is the maximum absolute adsorption capacity of the monolayer adsorption, $p$ is the equilibrium pressure, and $p_{L}$ is the Langmuir pressure defined as the pressure at which the amount of adsorbed methane molecules equals half of the maximum adsorption capacity.

Considering the heterogeneity of adsorption sites in adsorbents, Sips (1948) established the Langmuir-Freundlich (L-F) adsorption model extended from the Langmuir equation. The L-F equation is expressed as

$$
n_{a b}=\frac{n_{L}(b p)^{m}}{1+(b p)^{m}}
$$

At lower concentrations, it can be simplified to the Freundlich adsorption model. When $m=1$, the L-F adsorption model is simplified to a Langmuir adsorption model. Similarly, the LF-based excess adsorption model is

$$
n_{\mathrm{ex}}=\frac{n_{L}(b p)^{m}}{1+(b p)^{m}}\left(1-\frac{\rho_{\mathrm{g}}}{\rho_{\mathrm{a}}}\right)
$$

\section{Experiments and results}

\subsection{Experiments}

Seven core samples were collected from the Lower Silurian Longmaxi Formation (LSLF) in the northeast Chongqing area near the Sichuan Basin, China (Table 1). The organic-rich shale of LSLF in this area is mainly composed of black shale, black mud-shale, carbonaceous mud-shale, and siliceous shale 


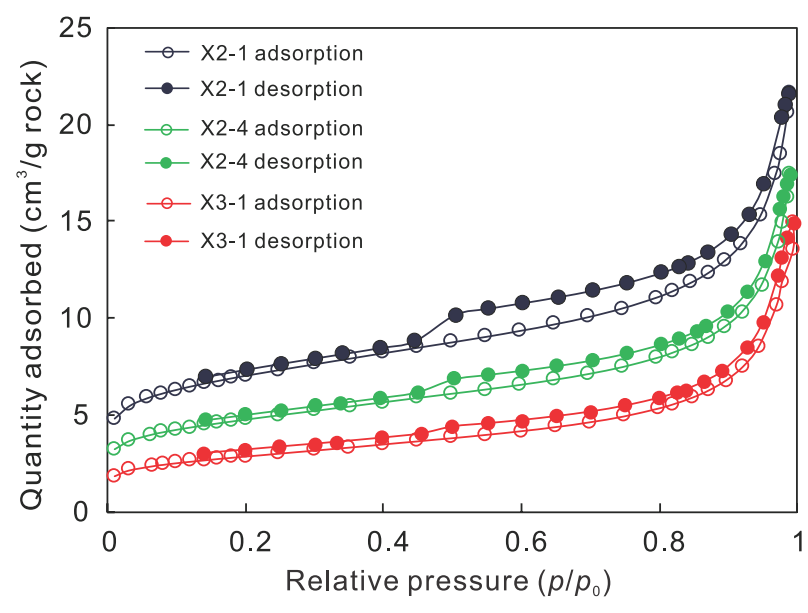

(a)

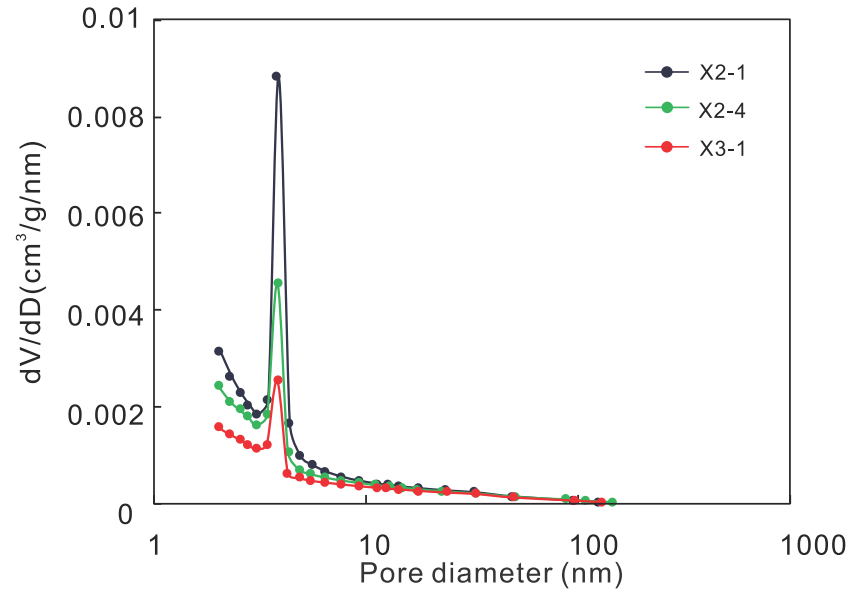

(b)

Fig. 1. (a) Low pressure nitrogen adsorption isotherms of all three representative samples at $77 \mathrm{~K}$; (b) The pore size distribution analyzed by BJH equation.

(Liang et al., 2016). The total organic carbon (TOC) content, low pressure nitrogen adsorption (LPNA) and high-pressure methane adsorption experiments were strictly conducted, and the detailed experimental procedures were presented in our previous study (Zhou et al., 2018b).

In this study, we have conducted SEM experiments as a supplement to analyze the nanopore structure of the shale samples. Small offcut block samples were polished to create a level surface using dry emery paper and were then milled by argon-ion. After polishing, the samples were coated with carbon atoms to enhance the surface conductivity. The samples were inserted into FEI Helios NanoLab ${ }^{\mathrm{TM}} 650$ DualBeam $^{\mathrm{TM}}$ system for imaging. The SEM images were taken on the newly milled shale surface with a $4 \mathrm{~mm}$ working distance and 10 $\mathrm{kV}$ accelerating voltage for the secondary electron (SE) mode (Zhou et al., 2016).

\subsection{Results}

According to the BDDT (Brunauer-Deming-DemingTeller) adsorption isotherm classification (Brunauer et al., 1940), nitrogen adsorption isotherms of shale samples belong to type IV (Fig. 1(a)), which indicates that nitrogen adsorption in shale can be divided into three stages: monolayer adsorption, multilayer adsorption, and capillary condensation (Li et al., 2016). The specific surface area (SSA), pore volume (PV) and pore size distribution (PSD) can be obtained by the isotherms using BET and BJH equations. In our LPNA experiments, the PSD curves exhibit the unimodal nature for most of the shale samples, and the peak is at approximately 4 $\mathrm{nm}$ (Fig. 1(b)), which is consistent with the results conducted by other researchers for Longmaxi shale (Wang et al., 2016b; Yang et al., 2016). The mesopore volumes of the shale samples are mainly contributed by the pores with width between 2 and $10 \mathrm{~nm}$, which is also consistent with the observations in Wang et al. (2016b).

The SEM results in Fig. 2 also show that the shale samples have abundant nanometer-scale pores and a small amount of

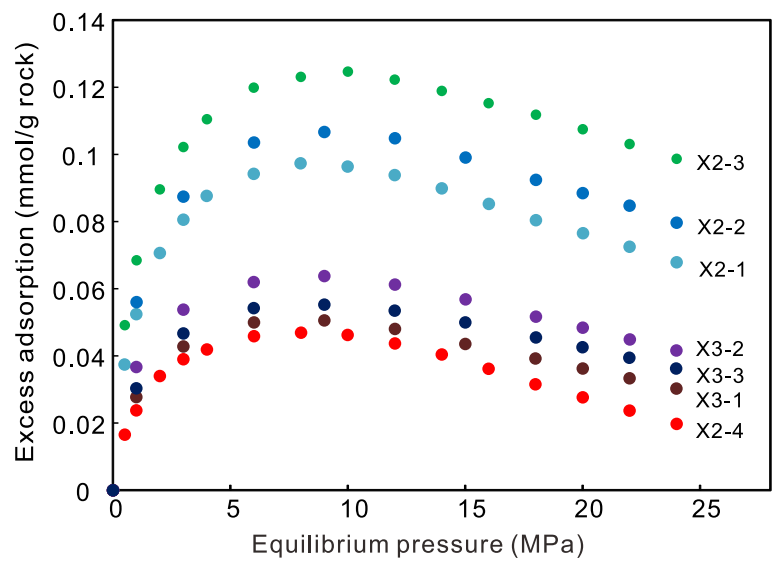

Fig. 3. High pressure methane adsorption isotherms of all the samples at $333.15 \mathrm{~K}$

micrometer-scale pores, mainly ranging from 5 to $200 \mathrm{~nm}$. The majority of pores are in organic matter (OM), which is caused mainly by the thermal evolution process (Curtis et al., 2012; Mastalerz et al., 2013). Numerous OM pores provide a very large specific surface area, which creates a favorable condition for gas adsorption and storage. This is also an important reason that the amount of shale gas adsorption is positively correlated with the TOC.

In Fig. 3, it can be observed that all the measured excess adsorption isotherms increase to the maximum values at the pressure of approximately $10 \mathrm{MPa}$, and then decline with pressure. This commonly-known phenomenon is attributed to the fact that the volume of the adsorbed phase increases with pressure (Tian et al., 2016; Tamg et al., 2017). When the pressure is high, the volume of the adsorbed phase cannot be neglected, and the excess adsorption capacity would decrease according to Eq. (3). Moreover, the maximum excess adsorption capacity $\left(n_{e x-\max }\right)$ is positively correlated with SSA and PV of micropores as found in our previous studies (Zhou et al., 2018b). However, there is no positive correlation between $n_{e x-\max }$ and PV for the mesopores. The difference of the 


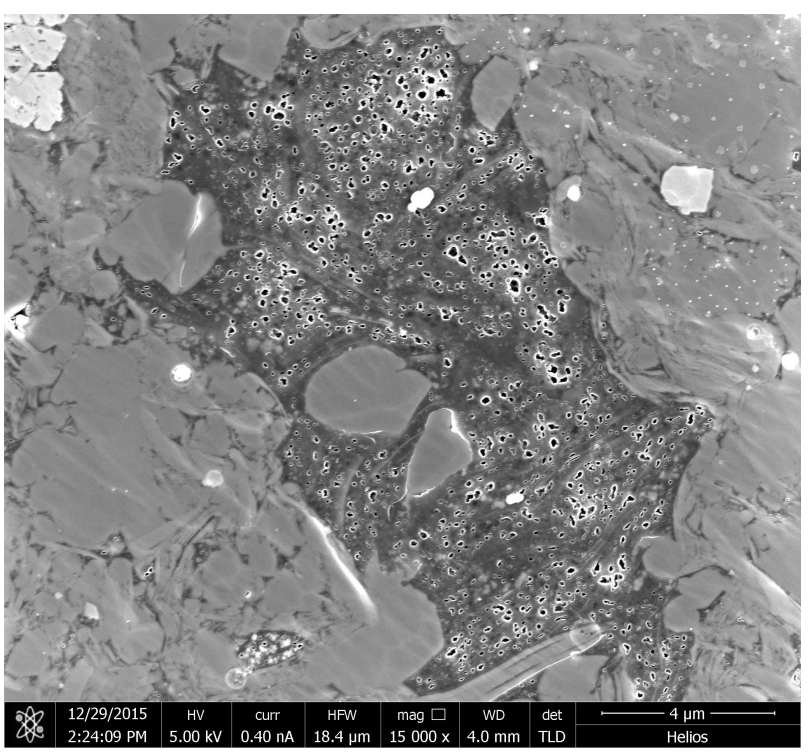

(a)

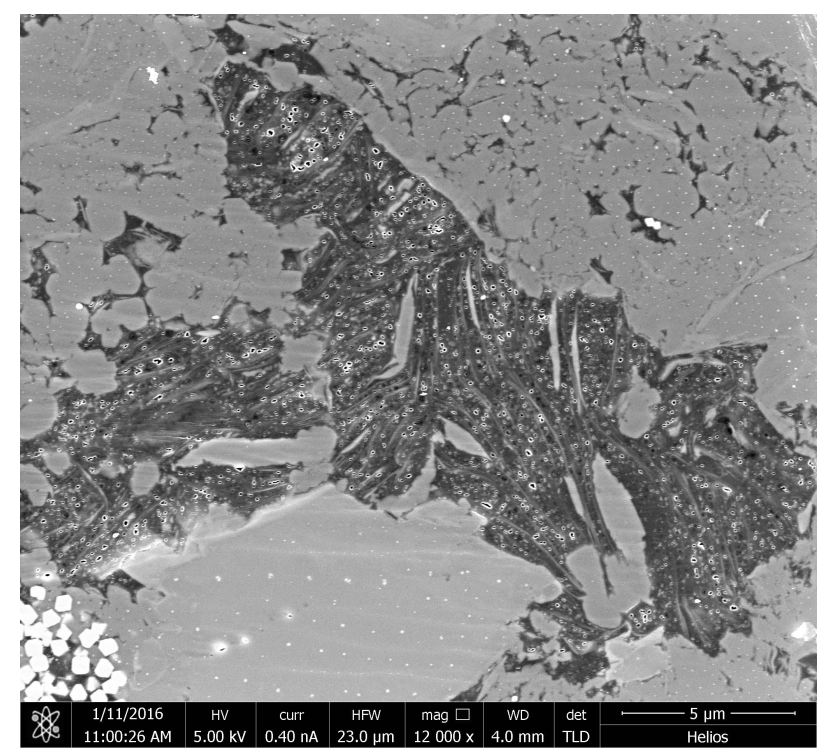

(b)

Fig. 2. SEM results of polished shale samples. Abundant pores are developed in organic matter and are mainly nanometer-sized (5-200 nm).

correlation coefficient of micropores and mesopores (Zhou et al., 2018b) indicates that the adsorbed gas might be mainly stored in micropores due to much higher interactions between gas molecules and micropores walls. This predictive viewpoint will be proved and discussed in the following sections.

\section{Discussion}

\subsection{Hypothesis and proof of adsorption mechanism}

Our previous studies have shown that the DR-based and Langmuir-based excess adsorption models perfectly fitted the observed isotherms (Zhou et al., 2018b). However, we are unable to determine whether the methane adsorption mechanism is micropore filling or monolayer adsorption or coexisting of both. It can be further proved by the following two hypotheses.

\subsubsection{Hypothesis I}

If we assume that all adsorbed methane molecules are filled in micropores, yielding that the only adsorption mechanism is micropore filling, the isotherms can be fitted by the DAbased excess adsorption model (Eq. (4)). The fitting results are presented in Fig. 4(a), showing the micropore filling theory can well describe the adsorption process. We can calculate the adsorbed-phase volume filled in micropores by Eq. (8).

$$
V_{a-\text { micro }}=\frac{M_{C H_{4}} \times n_{0}}{1000 \rho_{a}}
$$

where $V_{a-m i c r o}$ is the entire adsorbed-phase volume filled in micropores, $M_{C_{4}}$ is the molar mass of methane, $n_{0}$ and $\rho_{a}$ are the adsorption capacity and the density of adsorbed methane fitted by the DA-based excess adsorption model (Eq. (4)), respectively.
Fig. 4(b) shows the comparisons between adsorbed-phase volume $\left(V_{a-\text { micro }}\right)$ and micropore volume $\left(V_{\text {micro }}\right)$, Notice that $V_{a-\text { micro }}$ is much larger than $V_{\text {micro }}$ for all shale samples. However, $V_{a-\text { micro }}$ should be always smaller than or equal to $V_{\text {micro }}$ based on the assumption that the micropore filling is the only mechanism for methane adsorption, indicating that the hypothesis I is not valid.

\subsubsection{Hypothesis II}

Assuming that all the adsorbed methane molecules are monolayered in mesopores neglecting the affinity of micropore walls, we can fit the isotherms by the LF-based excess adsorption model (Eq. (7)). Fig. 5(a) shows that the LF-based excess adsorption model also fits the isotherms quite well, indicating that the monolayer adsorption mechanism is also possible. We can calculate the adsorbed-phase volume in mesopores by Eq. (9).

$$
V_{a-m e s o}=\frac{M_{C_{4}} \times n_{L}}{1000 \rho_{a}}
$$

where $V_{a-m e s o}$ is the adsorbed-phase volume in mesopores, $n_{L}$ and $\rho_{a}$ are the adsorption capacity and the density of adsorbed methane fitted by the LF-based excess adsorption model (Eq. (7)), respectively. Fig. 5(b) shows the comparisons between the calculated adsorbed-phase volume $V_{a-m e s o}$ and the volume of mesopores $V_{\text {meso }}$. We can see that $V_{a-m e s o}$ is much less than $V_{\text {meso }}$, which seems reasonable. To prove the rationality of this hypothesis, the number of adsorption layers (n) should be further investigated. The average number of layers be calculated by the following Eqs. (10) and (11) (Zhou et al., 2003),

$$
n=\frac{V_{a-\text { meso }}}{1000 \times S_{\text {meso }} \times \sigma}
$$




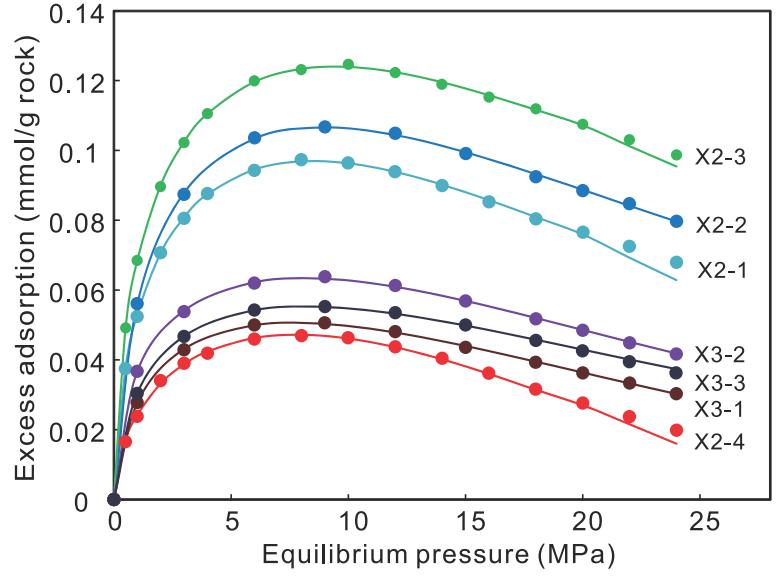

(a)

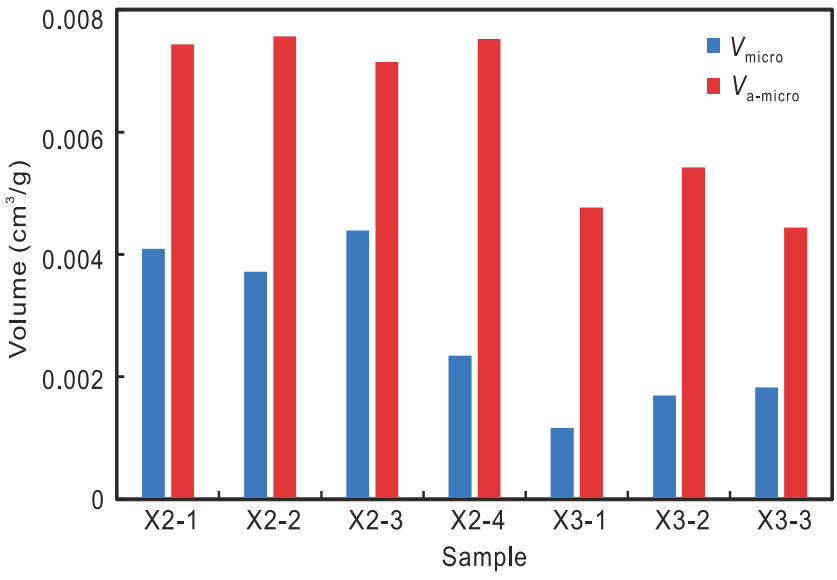

(b)

Fig. 4. (a) The fitting results of the excess adsorption isotherms of the seven samples using DA-based excess adsorption model (solid lines) based on micropore filling mechanism. The solid points represent the observed adsorption capacities under different pressures; (b) The comparison results between the micropore volume $\left(V_{\text {micro }}\right)$ and adsorbed-phase volume $\left(V_{\text {micro }}\right)$ after assuming all the adsorbed methane molecules are filled in micropores.

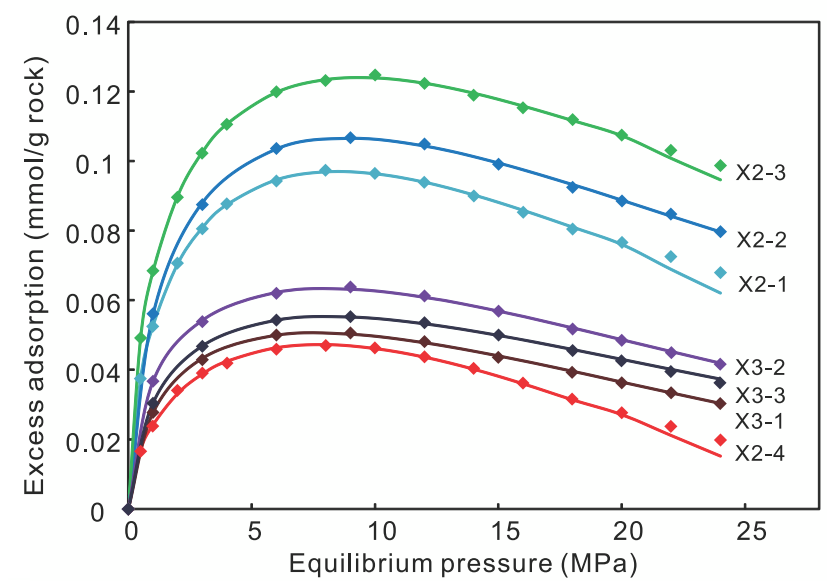

(a)

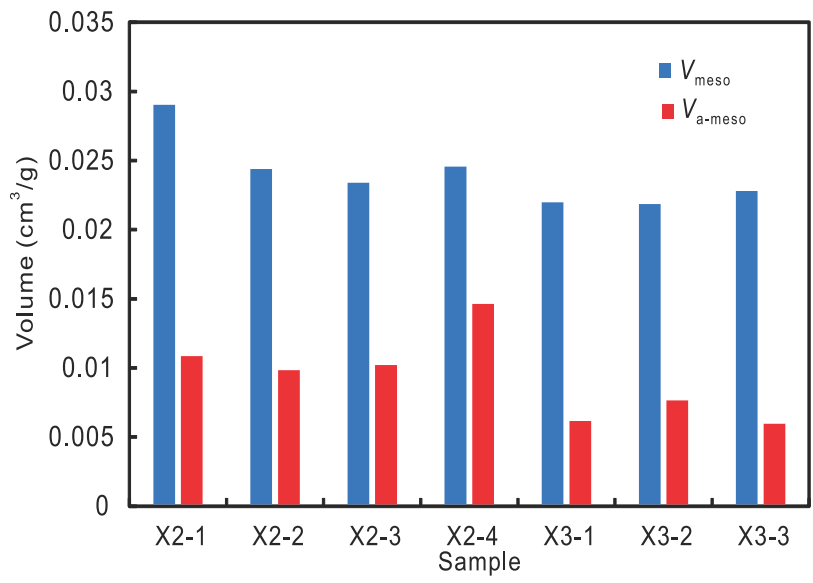

(b)

Fig. 5. (a) The fitting results of the excess adsorption isotherms of the seven samples using LF-based excess adsorption model (solid lines) based on micropore filling mechanism. The solid symbols represent the observed adsorption capacities under different pressures; (b) The comparison results between the mesopore volume $\left(V_{\text {meso }}\right)$ and adsorbed-phase volume $\left(V_{\text {meso }}\right)$ after assuming all the adsorbed methane molecules are monolayer-covered in mesopores.

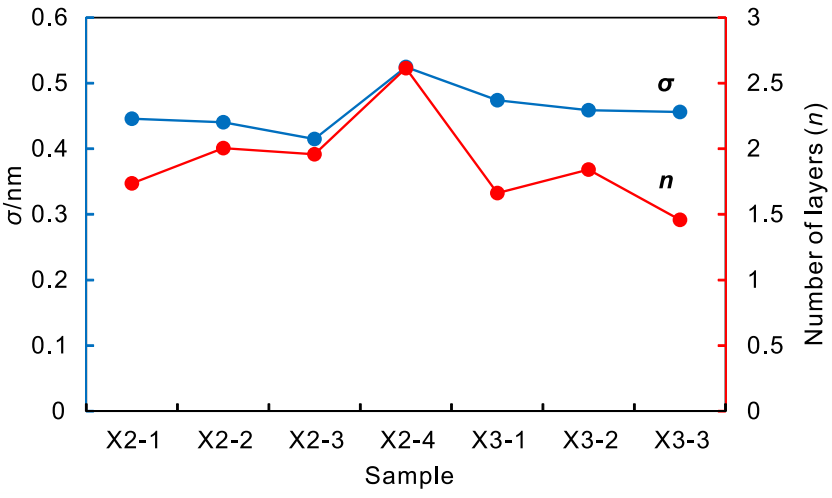

Fig. 6. The calculated average diameter of an adsorbed molecule $(\sigma)$ as shown by blue solid points and the average number of adsorption layers $(n)$ as shown by red solid points based on the hypothesis II.

$$
\sigma=\left(\frac{16}{\rho_{\mathrm{a}} N_{\mathrm{A}}}\right)^{\frac{1}{3}}
$$

where $n$ is the average number of adsorption layers, $V_{a-m e s o}$ is the adsorbed-phase volume in mesopores, $S_{\text {meso }}$ is the surface area of mesopores, $\sigma$ is the average diameter of an adsorbed molecule, and $N_{A}$ is the Avogadro number. Fig. 6 shows the calculated results of $n$. The average number of adsorption layers is ranging from 1.45 to 2.6 for all shale samples that are always higher than one, so that multi-layer adsorption mechanism becomes the only explanation in mesopores. However, this conclusion is contradictive with the assumption of the monolayer coverage mechanism. Therefore, the hypothesis II is also not valid.

In conclusion, neither of the above two hypotheses is reasonable. That is to say, the supercritical methane adsorption 
Table 2. Fitted parameters by the novel DA-LF adsorption model proposed in this paper (Eq. (12)) for the seven samples.

\begin{tabular}{|c|c|c|c|c|c|c|c|c|}
\hline Model & Parameter & $\mathrm{X} 2-1$ & $\mathrm{X} 2-2$ & $\mathrm{X} 2-3$ & $\mathrm{X} 2-4$ & X3-1 & $\mathrm{X} 3-2$ & X3-3 \\
\hline \multirow{8}{*}{ DA-LF } & $n_{0}$ & 0.098 & 0.112 & 0.128 & 0.066 & 0.054 & 0.071 & 0.075 \\
\hline & $\rho_{a}$ & 0.380 & 0.350 & 0.476 & 0.208 & 0.258 & 0.290 & 0.277 \\
\hline & $D$ & 0.011 & 0.009 & 0.010 & 0.069 & 0.062 & 0.068 & 0.044 \\
\hline & $k$ & 2.851 & 3.088 & 2.833 & 2.071 & 2.381 & 2.261 & 2.214 \\
\hline & $n_{L}$ & 0.029 & 0.031 & 0.030 & 0.008 & 0.026 & 0.043 & 0.010 \\
\hline & $b$ & 0.222 & 0.160 & 0.208 & 0.139 & 7.836 & 0.047 & 0.092 \\
\hline & $m$ & 2.203 & 2.205 & 2.033 & 5.056 & 0.225 & 0.010 & 2.295 \\
\hline & RSS & $1.25 \times 10^{-6}$ & $9.97 \times 10^{-7}$ & $1.15 \times 10^{-6}$ & $7.92 \times 10^{-7}$ & $4.22 \times 10^{-7}$ & $4.17 \times 10^{-7}$ & $3.27 \times 10^{-7}$ \\
\hline \multirow{5}{*}{ D-A } & $n_{0}$ & 0.146 & 0.154 & 0.177 & 0.088 & 0.076 & 0.096 & 0.081 \\
\hline & $D$ & 0.078 & 0.055 & 0.055 & 0.214 & 0.071 & 0.082 & 0.061 \\
\hline & $k$ & 1.861 & 2.080 & 1.986 & 1.42 & 1.972 & 1.802 & 2.020 \\
\hline & $\rho_{a}$ & 0.316 & 0.326 & 0.398 & 0.188 & 0.256 & 0.284 & 0.292 \\
\hline & RSS & $1.65 \times 10^{-6}$ & $1.61 \times 10^{-6}$ & $1.67 \times 10^{-6}$ & $1.73 \times 10^{-6}$ & $6.71 \times 10^{-7}$ & $8.86 \times 10^{-7}$ & $3.32 \times 10^{-7}$ \\
\hline \multirow{5}{*}{ L-F } & $n_{L}$ & 0.201 & 0.189 & 0.234 & 0.166 & 0.093 & 0.129 & 0.102 \\
\hline & $b$ & 0.217 & 0.323 & 0.262 & 0.060 & 0.327 & 0.240 & 0.315 \\
\hline & $m$ & 0.658 & 0.745 & 0.645 & 0.617 & 0.751 & 0.630 & 0.717 \\
\hline & $\rho_{a}$ & 0.300 & 0.311 & 0.372 & 0.184 & 0.249 & 0.275 & 0.280 \\
\hline & RSS & $1.59 \times 10^{-6}$ & $2.47 \times 10^{-6}$ & $1.60 \times 10^{-6}$ & $2.03 \times 10^{-6}$ & $8.87 \times 10^{-7}$ & $1.41 \times 10^{-6}$ & $3.75 \times 10^{-7}$ \\
\hline
\end{tabular}

mechanism cannot be only micropore filling or only monolayer coverage. Therefore, we speculate that the adsorption mechanism is the coexistence of micropore filling and monolayer coverage.

\subsection{The novel DA-LF adsorption model}

Based upon the above analysis, we established a novel adsorption model combining micropore filling and monolayer coverage theory. This model is derived from the integration of the D-A and L-F adsorption models and is written as

$$
n_{\mathrm{ex}}=\left\{n_{0} \exp \left[-D\left[\ln \left(\frac{\rho_{\mathrm{a}}}{\rho_{\mathrm{g}}}\right)\right]^{k}\right]+\frac{n_{\mathrm{L}}(b P)^{m}}{1+(b P)^{m}}\right\}\left(1-\frac{\rho_{\mathrm{g}}}{\rho_{\mathrm{a}}}\right)
$$

The unknown parameters $\left(n_{0}, n_{L}, D, b, k, m\right.$, and $\left.\rho_{a}\right)$ can be obtained from experimental adsorption data via the leastsquares fitting analysis by Eq. (12), and the fitting error can be evaluated by the RSS (residual sum of squares). To minimize the RSS error, the seven independent fitting parameters must obey the following limits: $0<n_{0}<0.2 \mathrm{mmol} / \mathrm{g}, 0<D<1$, $k>1,0<n_{L}<0.2 \mathrm{mmol} / \mathrm{g}, b>0, m>0$. Once these unknown parameters are determined, the adsorption capacities can then be obtained for micropores and mesopores, respectively.

Fig. 7 shows the fitting results by the new DA-LF model, and perfect fittings are observed. As shown in Table 2, the value of $n_{0}$ ranges from 0.054 to $0.128 \mathrm{mmol} / \mathrm{g}$, which is much larger than the $n_{L}$ value that ranges from 0.008 to 0.043 $\mathrm{mmol} / \mathrm{g}$. This indicates that the maximum methane adsorption capacity in micropores is larger than that in mesopores.

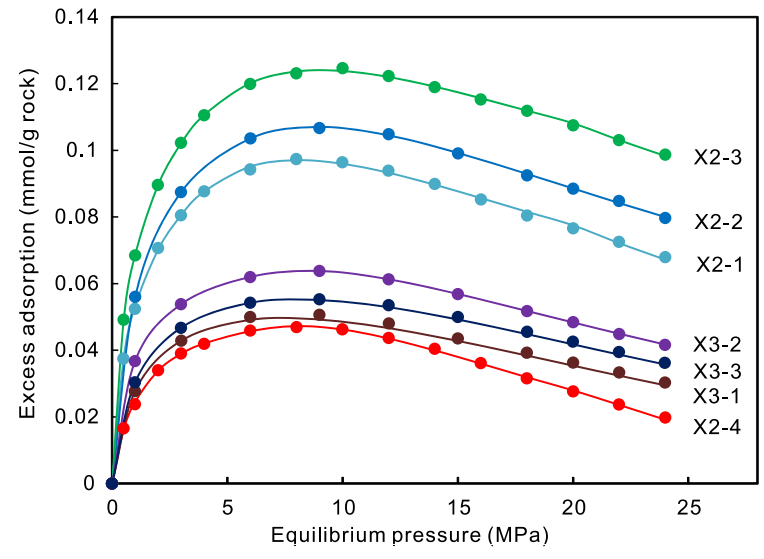

Fig. 7. The fitting results of the excess adsorption isotherms of the seven samples using the proposed DA-LF adsorption model (solid lines). The solid symbols represent the observed adsorption capacities under different pressures.

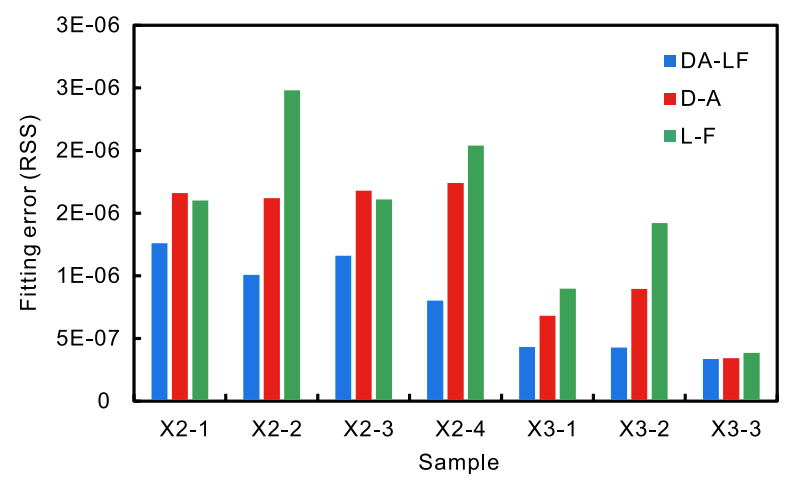

Fig. 8. Comparisons of fitting error using DA-LF, D-A, L-F adsorption model. 


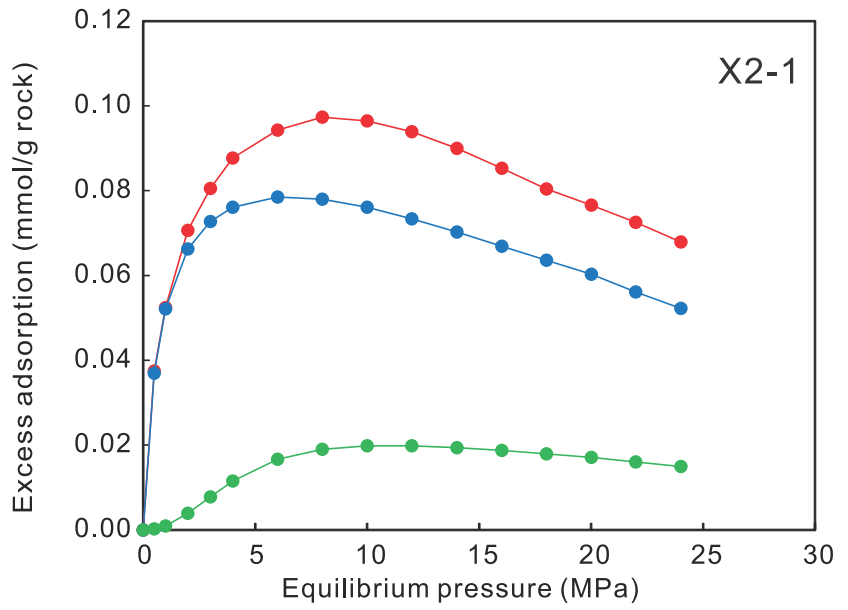

(a)

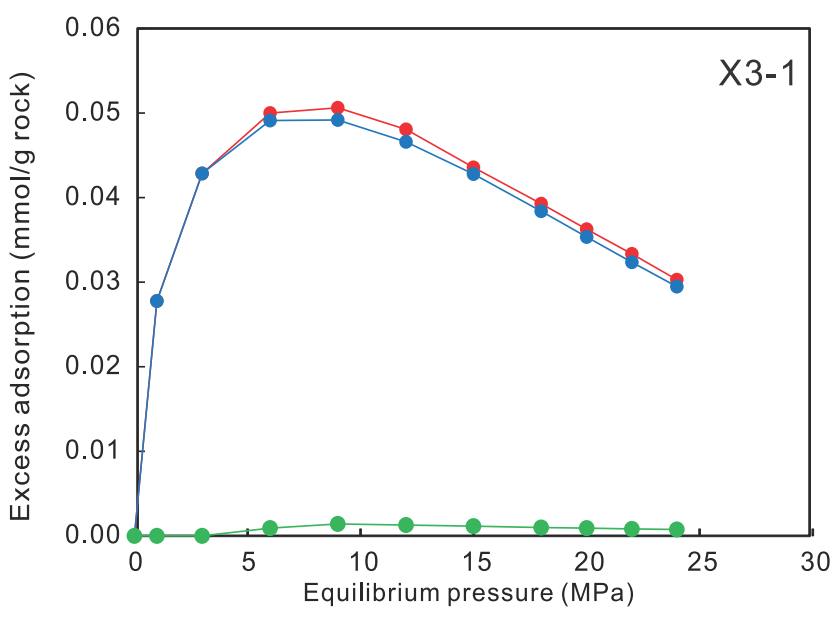

(c)

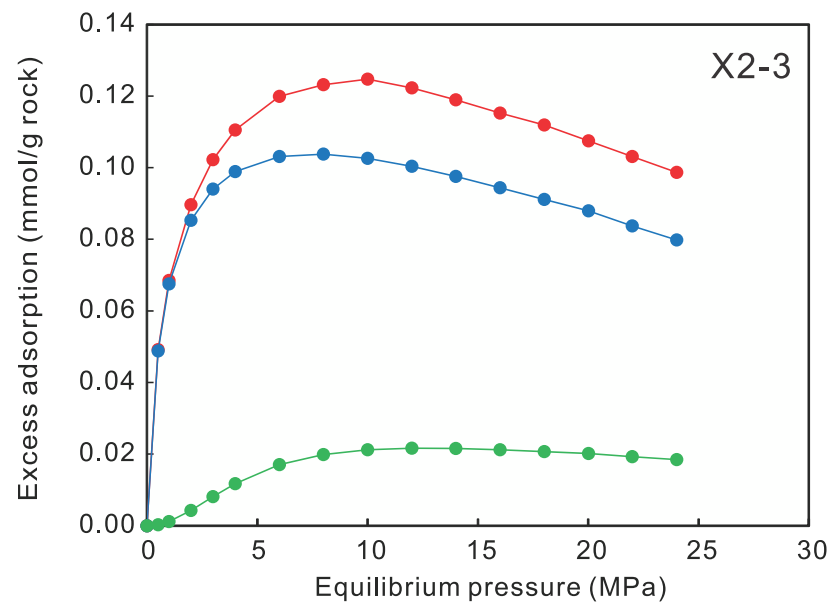

(b)

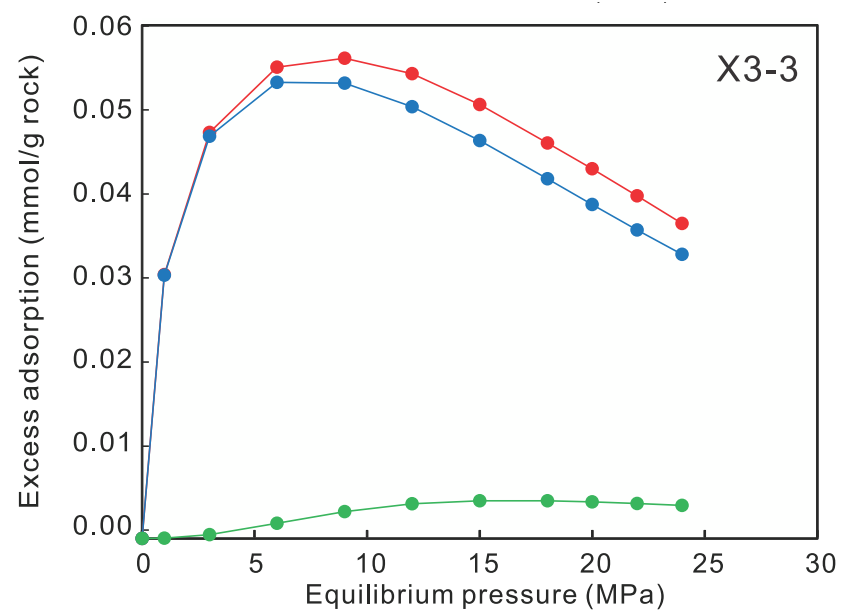

(d)

$\bullet$-Total $\rightarrow-$ Micropore filling $\rightarrow-$ Monolayer coverage

Fig. 9. The fitted excess adsorption isotherms of methane adsorbed in micropores and mesopores through micropore filling and monolayer coverage mechanism, respectively.

Compared with the D-A and L-F models, the fitting error of the new model is the smallest (Fig. 8) though the errors of all models are very small. The most important criteria to choose the suitable model is that it must correctly describe the internal mechanism of supercritical methane adsorption in shale. As mentioned above, the D-A model was established based on the micropore filling theory, describing the adsorption process in micropores $(<2 \mathrm{~nm})$; whereas, the L-F model was based the monolayer coverage theory, describing the adsorption process in mesopores $(2-50 \mathrm{~nm})$. However, pores in shale have a broad size distribution, ranging from nanometers to micrometers. Therefore, in order to accurately simulate the adsorption isotherms for the broad variety of pore sizes, neither of the D-A model and the L-F model works independently according to their assumptions. The proposed DA-LF adsorption model combines these two theories, and it covers the complete adsorption process in micropores and mesopores. Therefore, the new model is more suitable for shale.

\subsection{Comparison of adsorbed capacity in micropores and mesopores}

The total adsorption capacity is the sum of adsorptions in micropores and mesopores that are described by the first and second terms in the proposed model (Eq. (12)). Fitting the total adsorption isotherms using this model, we can obtain the individual adsorption isotherms for micropores and mesopores. Fig. 9 shows the methane adsorption isotherms in micropores and mesopores. Similar to the total adsorption capacity, the adsorption capacity in micropores also increases first and then decreases with pressure. Although both the surface area and pore volume of mesopores are larger than those of micropores, the adsorbed capacity in micropores is much larger than that in 


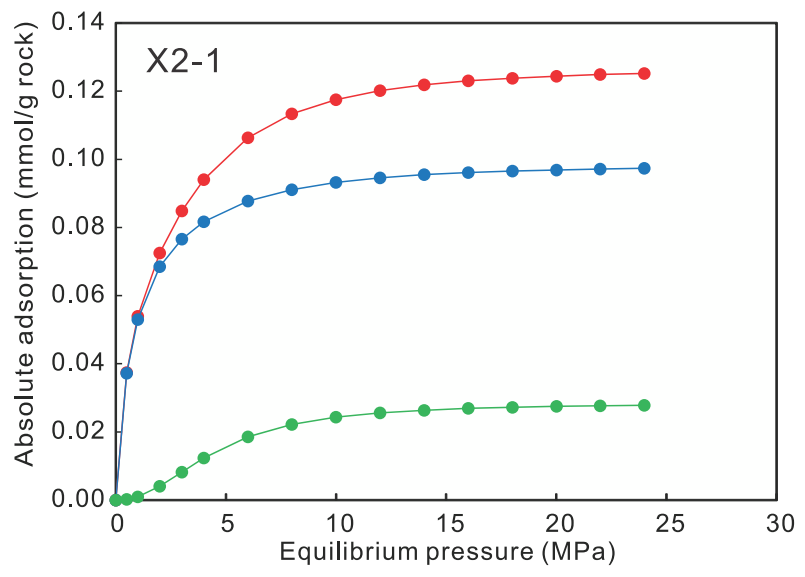

(a)

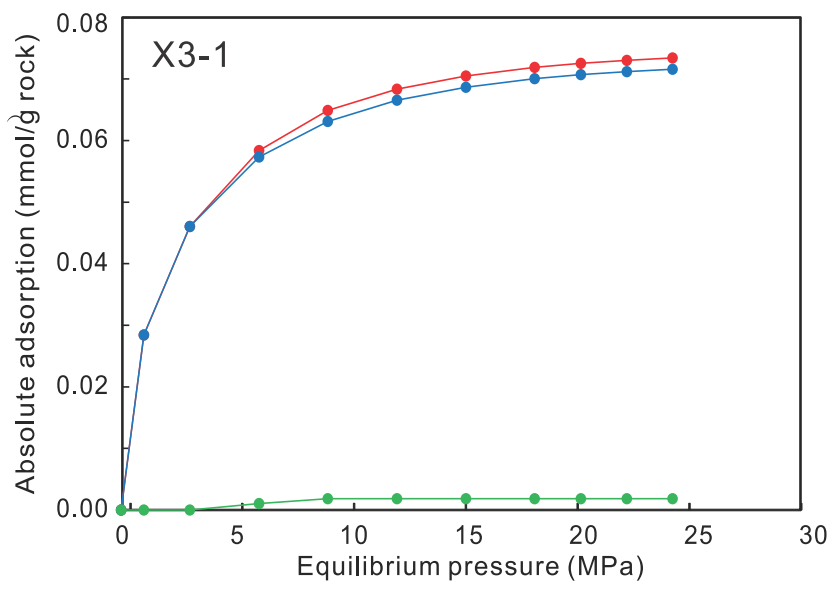

(c)

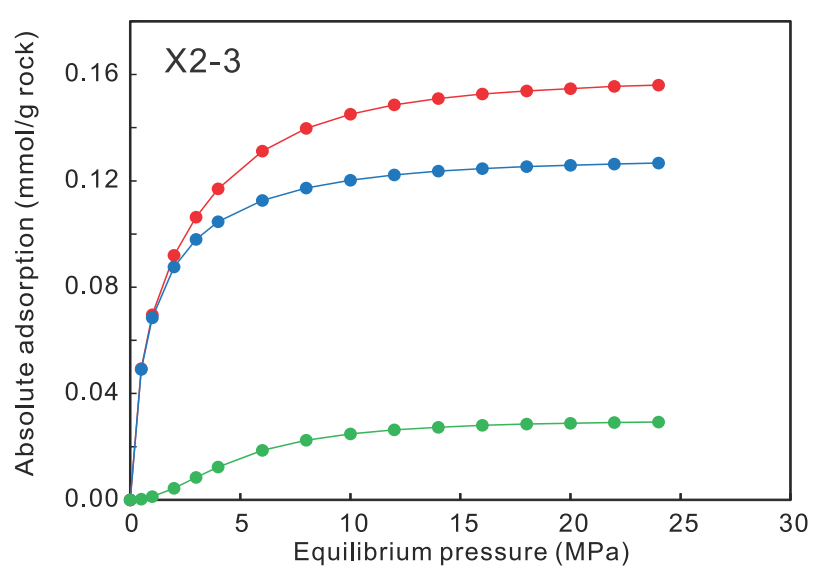

(b)

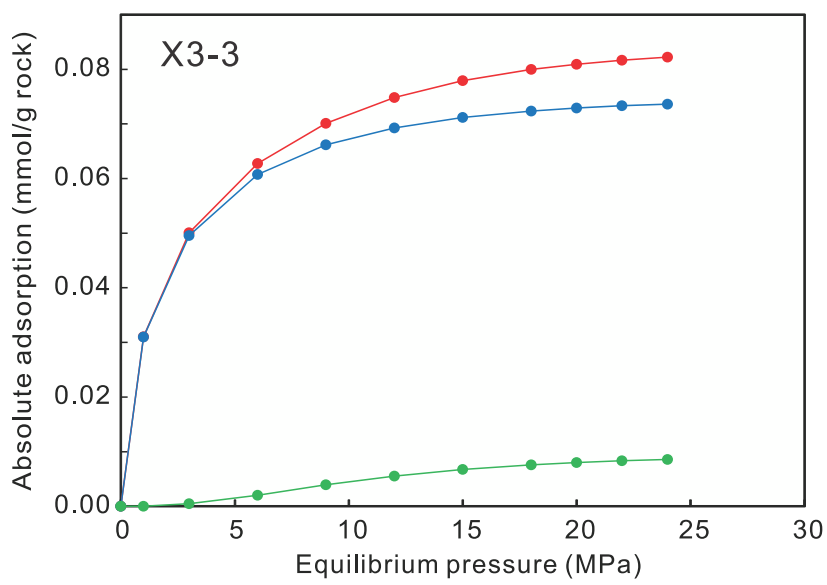

(d)

$\multimap-$ Total $\rightarrow$ Micropore filling $\multimap$ Monolayer coverage

Fig. 10. The calculated absolute adsorption isotherms of methane adsorbed in micropores and mesopores through micropore filling and monolayer coverage mechanism, respectively.

mesopores. This indicates that the methane molecules are more favorable in filling micropores than adsorbing on relatively flat surfaces in mesopores because the attractive interactions between methane molecules and micropore walls are much stronger.

The absolute adsorption isotherms represent the actual adsorption process in nanopores, and they can be obtained from the excess adsorption isotherms through Eq. (3). As shown in Fig. 10, all the absolute isotherms, including the total adsorption, the micropore adsorption, and the mesopore adsorption, increase monotonically with pressure whether it is occurred in the micropores or mesopores. We can see that at low pressures, while the adsorbed capacity in mesopores is nearly nothing, the adsorption capacity in micropores increases rapidly with pressure. At higher pressures, methane molecules are adsorbed in micropores and mesopores simultaneously until the saturation is reached.

The proportions of methane adsorbed in micropores and mesopores can also be calculated, respectively. Fig. 11 shows that the methane adsorption in micropores accounts for $77 \%$ to $97 \%$ of the total adsorption capacity, with an average of $86 \%$, which is far greater than that in the mesopores. The primary force related to gas adsorption include the interactions between gas molecules and pore surfaces, the interactions between pore surfaces in extremely confined pores, and the interactions between gas molecules themselves either in a free gas state or an adsorbed state (Mosher et al., 2013). We can infer that if the size of a micropore is comparative with an adsorbed gas molecule, the forces from the opposing walls will be more significant as well as forces from the neighboring molecules adsorbed to the pore walls. Therefore, the affinity of micropore surfaces is much stronger than that of mesopores surfaces, leading to the fact that methane molecules are primarily adsorbed in micropores.

\subsection{Methane adsorption mechanism}

The methane adsorption mechanism is a basic and key 


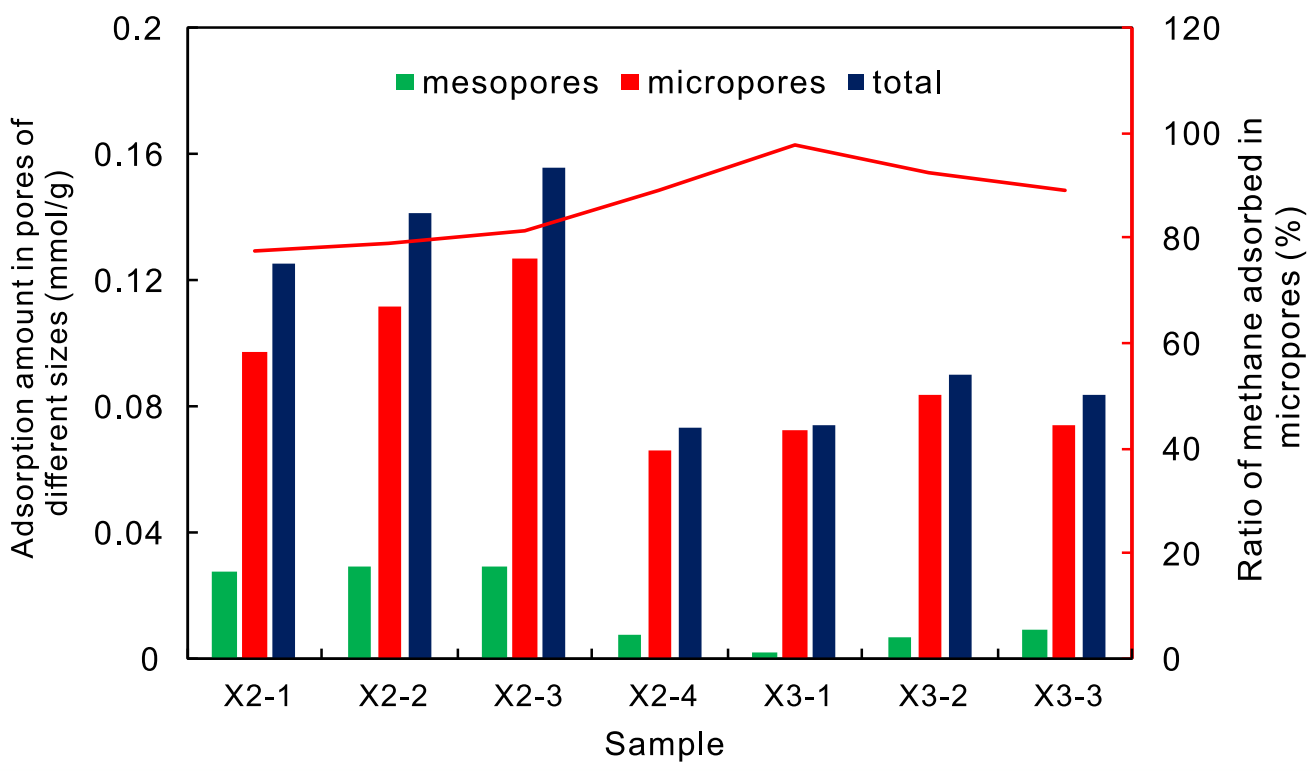

Fig. 11. Comparison between methane adsorption capacity in micropores and mesopores. The red line represents the ratio of methane adsorbed in micropores.

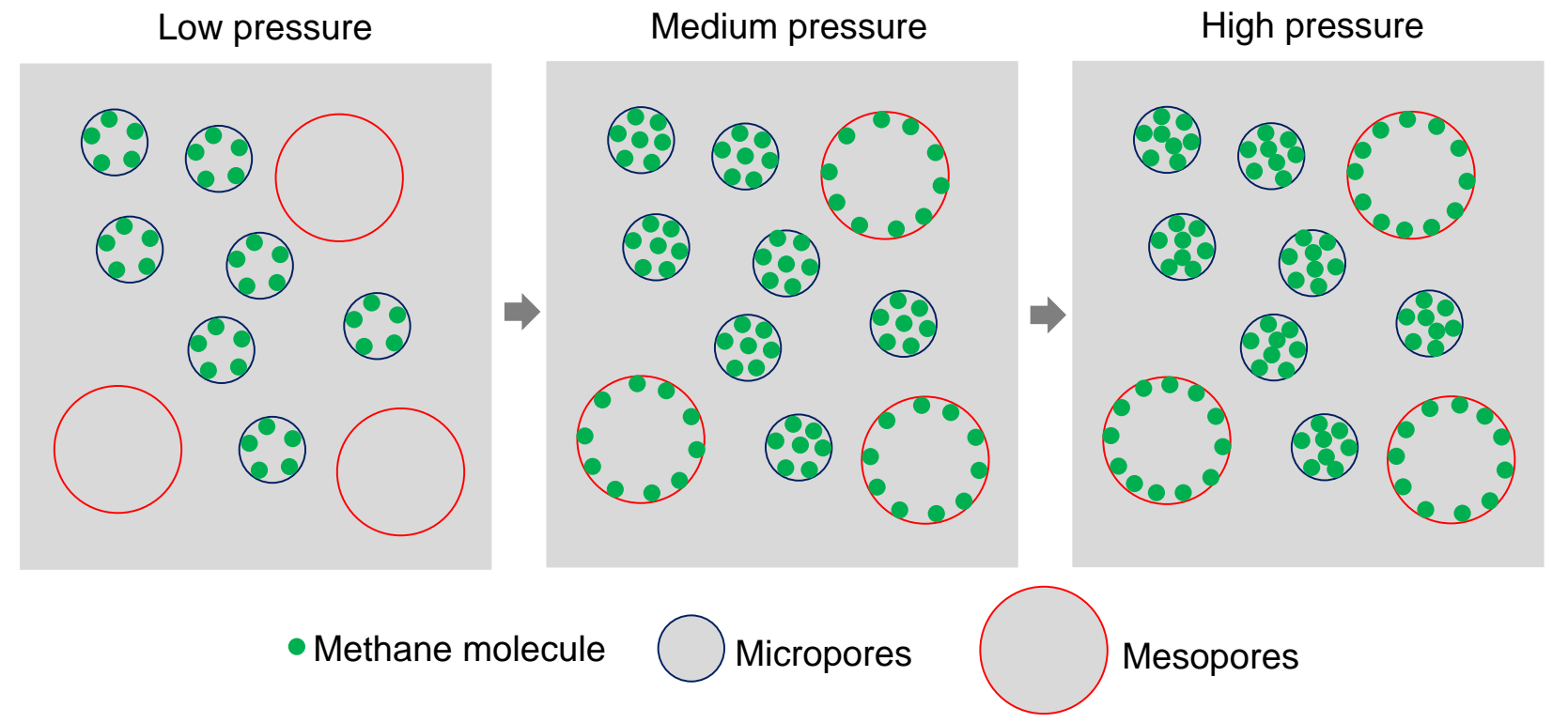

Fig. 12. Schematic diagram of methane adsorption process and mechanism from low pressure to high pressure based on discussions made in this study.

issue for understanding the shale gas storage and transport in nanopores. In the literature, most researchers have studied the methane adsorption mechanism by molecular simulations, and they stated that methane is double-layer adsorbed in nanopores. Mosher et al. (2013) simulated methane adsorption in nanopores from $0.4 \mathrm{~nm}$ to $9 \mathrm{~nm}$ and observed two adsorption layers at high pressures. Xiong et al. (2017) also indicated that the adsorbed methane in nanopores changed from a monolayer to multilayers with the increase of pore size or pressure. However, the adsorbent materials used in simulation studies are mostly homogeneous, and the pore is fixed at a single size (Mosher et al., 2013; Chen et al., 2017; Xiong et al., 2017; Huang et al., 2018), which are completely different from the heterogeneous nature of shale.

In this study, we have taken into account the different adsorption mechanisms of methane for different-sized nanopores, and we established a new model to characterize the whole adsorption process. Based on the above discussions, we hold the opinion that the methane adsorption mechanism in shale is: the majority of methane molecules are filled in micropores, and the remainder are monolayer-adsorbed in mesopores. Fig. 12 shows the adsorption process of methane in nanopores for three stages. When the pressure is low, methane molecules are only adsorbed in micropores by filling; as the pressure increases, methane molecules begin to invade and adsorb on mesopore surface as monolayer coverage; when the pressure is 
high enough, micropores are fully filled by methane molecules, and mesopores are partially covered until surface is saturated.

\section{Conclusions}

The conclusions can be drawn from the results of the current study as follows:

1) From two hypotheses, we have proved that separate use of the micropore filling theory or the monolayer adsorption theory are unable to explain the true methane adsorption mechanism in shale. Methane should be not only adsorbed in micropores $(<2 \mathrm{~nm})$ but also in mesopores (2-50 nm).

2) Combining the micropore filling and monolayer coverage theories, we established a novel DA-LF model that can fit the high-pressure isotherms quite well. The fitting error of this new model is slightly smaller than the commonly used D-A and L-F models.

3) The adsorption isotherms and capacity in micropores and mesopores can be calculated using this new model separately. We also found that methane is mainly adsorbed in micropores, and the adsorbed methane in micropores accounts for $77 \%$ to $97 \%$ of the total adsorption capacity.

4) Considering different adsorption mechanisms for different-sized pores, we can conclude that the methane adsorption mechanism in shale is: the majority of molecules are filled in micropores, and the remainder are monolayer-adsorbed in mesopores.

\section{Acknowledgments}

This study was funded by National Science and Technology Major Project (No. 2017ZX05035002-002).

Open Access This article is distributed under the terms and conditions of the Creative Commons Attribution (CC BY-NC-ND) license, which permits unrestricted use, distribution, and reproduction in any medium, provided the original work is properly cited.

\section{References}

Amankwah, K.A.G., Schwarz, J.A. A modified approach for estimating pseudo-vapor pressures in the application of the Dubinin-Astakhov equation. Carbon 1995, 33(9): 1313-1319.

Ambrose, R.J., Hartman, R.C., Diaz-Campos, M., et al. New pore-scale considerations for shale gas in place calculations. Paper SPE 131772 present at the SPE Unconventional Gas Conference, Pittsburgh, Pennsylvania, USA, 23-25 February, 2010.

Ambrose, R.J., Hartman, R.C., Diaz-Campos, M., et al. Shale gas-in-place calculations part I: new pore-scale considerations. SPE J. 2012, 17(1): 219-229.

Aranovich, G.L., Donohue, M.D. Adsorption of supercritical fluids. J. Colloid Interface Sci. 1996, 180(2): 537-541.

Bi, H., Jiang, Z., Li, J., et al. The Ono-Kondo model and an experimental study on supercritical adsorption of shale gas: A case study on Longmaxi shale in southeastern Chongqing, China. J. Nat. Gas Sci. Eng. 2016, 35: 114121.
Brunauer, S., Deming. L.S., Deming, W.E., et al. On a theory of the van der Waals adsorption of gases. J. Am. Chem. Soc. 1940, 62(7): 1723-1732.

Brunauer, S., Emmett, P.H., Teller, E. Adsorption of gases in multimolecular layers. J. Am. Chem. Soc. 1938, 60(2): 309-319.

Chareonsuppanimit, P., Mohammad, S.A., Robinson, Jr.R.L., et al. High-pressure adsorption of gases on shales: Measurements and modeling. Int. J. Coal Geol. 2012, 95: 34-46.

Chen, G., Lu, S., Zhang, J., et al. Keys to linking GCMC simulations and shale gas adsorption experiments. Fuel 2017, 199: 14-21.

Clarkson, C.R., Bustin, R.M., Levy, J.H. Application of the mono/multilayer and adsorption potential theories to coal methane adsorption isotherms at elevated temperature and pressure. Carbon 1997, 35(12): 1689-1705.

Clarkson, C.R., Haghshenas, B. Modeling of supercritical fluid adsorption on organic-rich shales and coal. Paper SPE 164532 present at the SPE Unconventional Resources Conference, The Woodlands, Texas, USA, 10-12 April, 2013.

Curtis, J.B. Fractured shale-gas systems. AAPG Bull. 2002, 86(11): 1921-1938.

Curtis, M.E., Cardott, B.J., Sondergeld, C.H., et al. Development of organic porosity in the Woodford Shale with increasing thermal maturity. Int. J. Coal Geol. 2012, 103: 26-31.

Do, D.D. Adsorption analysis: equilibria and kinetics. London, UK, Imperial college press, 1998.

Do, D.D., Do, H.D. Adsorption of supercritical fluids in nonporous and porous carbons: analysis of adsorbed phase volume and density. Carbon 2003, 41(9): 1777-1791.

Dubinin, M.M. Adsorption in micropores. J. Colloid Interface Sci. 1967, 23(4): 487-499.

Dubinin, M.M., Astakhov, V.A. Development of the concepts of volume filling of micropores in the adsorption of gases and vapors by microporous adsorbents. Russ. J. Phys. Chem. B 1971, 20(1): 3-7.

Findnegg, G.H. High pressure physical adsorption of gases on homogeneous surfaces, in Fundamentals of Adsorption, edited by A. L. Myers, G. Belfort, A.I.O.C. Engineers,et al., American Institute of Chemical Engineers, New York, pp. 207-219, 1983.

Foo, K.Y., Hameed, B.H. Insights into the modeling of adsorption isotherm systems. Chem. Eng. J. 2010, 156(1): 2-10.

Gasparik, M., Ghanizadeh, A., Bertier, P., et al. High-pressure methane sorption isotherms of black shales from the Netherlands. Energy Fuels 2012, 26(8): 4995-5004.

Hao, S., Chu, W., Jiang, Q., et al. Methane adsorption characteristics on coal surface above critical temperature through Dubinin-Astakhov model and Langmuir model. Colloid Surf. A 2014, 444: 104-113.

He, S., Ning, Y., Chen, T., et al. Transport properties of natural gas in shale organic and inorganic nanopores using nonequilibrium molecular dynamics simulation. Paper IPTC 18875 Present at the International Petroleum Technology 
Conference, Bangkok, Thailand, 14-16 November, 2016.

Huang, L., Ning, Z., Wang, Q., et al. Molecular simulation of adsorption behaviors of methane, carbon dioxide and their mixtures on kerogen: Effect of kerogen maturity and moisture content. Fuel 2018, 211: 159-172.

Ji, W., Song, Y., Jiang, Z., et al. Estimation of marine shale methane adsorption capacity based on experimental investigations of Lower Silurian Longmaxi formation in the Upper Yangtze Platform, south China. Mar. Pet. Geol. 2015, 68: 94-106.

Jiao, K., Yao, S., Liu, C., et al. The characterization and quantitative analysis of nanopores in unconventional gas reservoirs utilizing FESEM-FIB and image processing: an example from the lower Silurian Longmaxi Shale, upper Yangtze region, China. Int. J. Coal Geol. 2014, 128: 1-11.

Langmuir, I. The adsorption of gases on plane surfaces of glass, mica and platinum. J. Am. Chem. Soc. 1918, 40(9): 1361-1403.

Li, A., Ding, W., Zhou, X., et al. Investigation of the methane adsorption characteristics of marine shale: A case study of lower cambrian qiongzhusi shale in eastern Yunnan Province, South China. Energy Fuels 2017, 31(3): 26252635.

Li, Z., Min, T., Kang, Q., et al. Investigation of methane adsorption and its effect on gas transport in shale matrix through microscale and mesoscale simulations. Int. J. Heat Mass Transf. 2016, 98: 675-686.

Liang, F., Bai, W., Zou, C., et al. Shale gas enrichment pattern and exploration significance of Well WuXi-2 in northeast Chongqing, NE Sichuan Basin. Pet. Explor. Dev. 2016, 43(3): 386-394.

Mastalerz, M., Schimmelmann, A., Drobniak, A., et al. Porosity of devonian and mississippian new albany shale across a maturation gradient: Insights from organic petrology, gas adsorption, and mercury intrusion. AAPG Bull. 2013, 97(10): 1621-1643.

Mikhail, R.S., Brunauer, S., Bodor, E.E. Investigations of a complete pore structure analysis: I. Analysis of micropores. J. Colloid Interface Sci. 1968, 26(1): 4553.

Milliken, K.L., Rudnicki, M., Awwiller, D.N., et al. Organic matter-hosted pore system, Marcellus formation (Devonian), Pennsylvania. AAPG Bull. 2013, 97(2): 177-200.

Montgomery, S.L., Jarvie, D.M., Bowker, K.A., et al. Mississippian barnett shale, fort worth basin, northcentral Texas: Gas-shale play with multi-trillion cubic foot potential. AAPG Bull. 2005, 89(2): 155-175.

Mosher, K., He, J., Liu, Y., et al. Molecular simulation of methane adsorption in micro-and mesoporous carbons with applications to coal and gas shale systems. Int. J. Coal Geol. 2013, 109: 36-44.

Pini, R., Ottiger, S., Burlini, L., et al. Sorption of carbon dioxide, methane and nitrogen in dry coals at high pressure and moderate temperature. Int. J. Greenhouse Gas Control 2010, 4(1): 90-101.

Rexer, T.F., Benham, M.J., Aplin, A.C., et al. Methane adsorption on shale under simulated geological temperature and pressure conditions. Energy Fuels 2013, 27(6): 3099-
3109.

Ross, D.J.K., Bustin, R.M. The importance of shale composition and pore structure upon gas storage potential of shale gas reservoirs. Mar. Pet. Geol. 2009, 26(6): 916-927.

Sakurovs, R., Day, S., Weir, S., et al. Application of a modified Dubinin Radushkevich equation to adsorption of gases by coals under supercritical conditions. Energy Fuels 2007, 21(2): 992-997.

Sing, K.S. Reporting physisorption data for gas/solid systems with special reference to the determination of surface area and porosity (Recommendations 1984). Pure. Appl. Chem. 1985, 57(4): 603-619.

Sips, R. On the structure of a catalyst surface. J. Chem. Phys. 1948, 16(5): 490-495.

Tang, X., Ripepi, N., Luxbacher, K., et al. Adsorption models for methane in shales: Review, comparison, and application. Energy Fuels 2017, 31(10): 10787-10801.

Tang, X., Ripepi, N., Stadie, N.P., et al. A dual-site Langmuir equation for accurate estimation of high pressure deep shale gas resources. Fuel 2016, 185: 10-17.

Tian, H., Li, T., Zhang, T., et al. Characterization of methane adsorption on overmature Lower Silurian-Upper Ordovician shales in Sichuan Basin, southwest China: Experimental results and geological implications. Int. J. Coal Geol. 2016, 156: 36-49.

Tian, H., Pan, L., Xiao, X., et al. A preliminary study on the pore characterization of Lower Silurian black shales in the Chuandong Thrust Fold Belt, southwestern China using low pressure $\mathrm{N}_{2}$ adsorption and FE-SEM methods. Mar. Pet. Geol. 2013, 48: 8-19.

Ushiki, I., Ota, M., Sato, Y., et al. Measurements and DubininAstakhov correlation of adsorption equilibria of toluene, acetone, n-hexane, n-decane and methanol solutes in supercritical carbon dioxide on activated carbon at temperature from 313 to $353 \mathrm{~K}$ and at pressure from 4.2 to 15.0 MPa. Fluid Phase Equilib. 2013, 344: 101107.

Wang, Y., Zhu, Y., Liu, S., et al. Methane adsorption measurements and modeling for organic-rich marine shale samples. Fuel 2016a, 172: 301-309.

Wang, Y., Zhu, Y., Liu, S., et al. Pore characterization and its impact on methane adsorption capacity for organic-rich marine shales. Fuel 2016b, 181: 227-237.

Wang, Z., Li, Y., Guo, P., et al. Analyzing the adaption of different adsorption models for describing the shale gas adsorption law. Chem. Eng. Technol. 2016c, 39(10): 1921-1932.

Weniger, P., Kalkreuth, W., Busch, A., et al. High-pressure methane and carbon dioxide sorption on coal and shale samples from the Paran Basin, Brazil. Chem. Eng. Technol. 2010, 84(3-4): 190-205.

Xiong, J., Liu, X., Liang, L., et al. Adsorption of methane in organic-rich shale nanopores: An experimental and molecular simulation study. Fuel 2017, 200: 299-315.

Yang, R. Gas Separation by Adsorption Processes. London, UK, Imperial College Press, 2013.

Yang, R., He, S., Yi, J., et al. Nano-scale pore structure and fractal dimension of organic-rich Wufeng-Longmaxi 
shale from Jiaoshiba area, Sichuan Basin: Investigations using FE-SEM, gas adsorption and helium pycnometry. Mar. Pet. Geol. 2016, 70: 27-45.

Yu, W., Sepehrnoori, K., Patzek, T.W. Modeling gas adsorption in Marcellus shale with Langmuir and bet isotherms. SPE J. 2016, 21(2): 589-600.

Zhang, T., Ellis, G.S., Ruppel, S.C., et al. Effect of organicmatter type and thermal maturity on methane adsorption in shale-gas systems. Org. Geochem. 2012, 47: 120-131.

Zhao, P., Cai, J., Huang, Z., et al. Estimating permeability of shale gas reservoirs from porosity and rock compositions. Geophysics 2018a, 83(5): 1-36.

Zhao, P., Ma, H., Rasouli, V., et al. An improved model for estimating the TOC in shale formations. Mar. Pet. Geol. 2017, 83: 174-183.
Zhou, L., Bai, S., Su, W., et al. Comparative study of the excess versus absolute adsorption of $\mathrm{CO}_{2}$ on superactivated carbon for the near-critical region. Langmuir 2003, 19(7): 2683-2690.

Zhou, S., Xue, H., Ning, Y., et al. Experimental study of supercritical methane adsorption in Longmaxi shale: Insights into the density of adsorbed methane. Fuel 2018b, 211: 140-148.

Zhou, S., Yan, G., Xue, H., et al. 2D and 3D nanopore characterization of gas shale in Longmaxi formation based on FIB-SEM. Mar. Pet. Geol. 2016, 73: 174-180.

Zou, C., Dong, D., Wang, Y., et al. Shale gas in China: Characteristics, challenges and prospects (II). Pet. Explor. Dev. 2016, 43(2): 182-196. 